\title{
BOARD OF GOVERNORS
}

In supersession of the Medical Council of India

\section{Telemedicine Practice Guidelines}

Enabling Registered Medical Practitioners to Provide Healthcare Using

Telemedicine

[This constitutes Appendix 5 of the Indian Medical Council (Professional Conduct, Etiquette and Ethics Regulation, 2002]

\section{March 2020}


These Guidelines have been prepared in partnership with NITI Aayog 
TABLE OF CONTENT

\begin{tabular}{|c|c|c|}
\hline S. No. & Description & Page No. \\
\hline & Background & 7 \\
\hline 1. & $\begin{array}{l}\text { Definitions } \\
\text { - Definition of Telemedicine } \\
\text { - Definition of Telehealth } \\
\text { - Definition of Registered Medical Practitioner } \\
\text { Scope of Telemedicine } \\
\text { RMP's are entitled to Practice Telemedicine } \\
\text { Telemedicine Applications } \\
\text { - Mode of Communication } \\
\text { - Timing of Information Transmitted } \\
\text { - Purpose of the consultation } \\
\text { - Individuals involved }\end{array}$ & 10 \\
\hline 2. & $\begin{array}{l}\text { Technology Used/ Mode of Communications } \\
\text { - Video, Audio, Text }\end{array}$ & 14 \\
\hline 3. & $\begin{array}{l}\text { Guidelines for Telemedicine in India } \\
\text { Elements specific to Telemedicine } \\
\text { - Appropriateness of Telemedicine } \\
\text { - Identification of RMP and the patient } \\
\text { - Appropriateness of technology/Mode of Telemedicine } \\
\text { - Patient Consent } \\
\text { - Patient Evaluation } \\
\text { - Patient Management: Health education, counseling and medication } \\
\text { Duties and responsibilities of RMP in general } \\
\text { - Medical Ethics, Data Privacy \& Confidentiality } \\
\text { - Documentation and Digital Records of Consultation } \\
\text { - Fee for Telemedicine }\end{array}$ & 16 \\
\hline 4. & $\begin{array}{l}\text { Framework for Telemedicine } \\
\text { - Patient to Registered Medical Practitioner } \\
\text { - } \quad \text { Care Giver to Registered Medical Practitioner } \\
\text { - } \quad \text { Patient to RMP through Health Worker at a Sub Center or any } \\
\text { - } \quad \text { peripheral center } \\
\end{array}$ & 25 \\
\hline 5. & Guidelines for Technology Platforms enabling Telemedicine & 33 \\
\hline 6. & Special Responsibilities of Board of Governors (BoG) in supersession to $\mathrm{MCl}$ & 34 \\
\hline 7. & Figures (Teleconsultation flow charts 1-3) & 35 \\
\hline 8. & $\begin{array}{l}\text { Annexures } \\
\text { 1. Drug List } \\
\text { 2. Sample Prescription Format }\end{array}$ & 43 \\
\hline
\end{tabular}




\section{TELEMEDICINE}

'The delivery of health care services, where distance is a critical factor, by all health care professionals using information and communication technologies for the exchange of valid information for diagnosis, treatment and prevention of disease and injuries, research and evaluation, and for the continuing education of health care providers, all in the interests of advancing the health of individuals and their communities.'

\section{TELEHEALTH}

'The delivery and facilitation of health and health-related services including medical care, provider and patient education, health information services, and self-care via telecommunications and digital communication technologies.'

\section{REGISTERED MEDICAL PRACTITIONER}

'A Registered Medical Practitioner [RMP] is a person who is enrolled in the State Medical Register or the Indian Medical Register under the Indian Medical Council Act 1956.' [IMC Act, 1956] 


\section{Background}

\section{Telemedicine: An Enabler of Healthcare Access and Affordability}

There are a number of benefits of telemedicine. It increases timely access to appropriate interventions including faster access and access to services that may not otherwise be available.

In India, providing In-person healthcare is challenging, particularly given the large geographical distances and limited resources. One of the major advantages of telemedicine can be for saving of cost and effort especially of rural patients, as they need not travel long distances for obtaining consultation and treatment. In this type of scenario, telemedicine can provide an optimal solution for not just providing timely and faster access. It would also reduce financial costs associated with travel. It also reduces the inconvenience/impact to family and caregivers and social factors. Telemedicine can play a particularly important role in cases where there is no need for the patient to physically see the RMP (or other medical professional), e.g. for regular, routine check-ups or continuous monitoring. Telemedicine can reduce the burden on the secondary hospitals.

With telemedicine, there is higher likelihood of maintenance of records and documentation hence minimalizes the likelihood of missing out advice from the doctor other health care staff. Conversely, the doctor has an exact document of the advice provided via tele-consultation. Written documentation increases the legal protection of both parties. Telemedicine provides patient's safety, as well as health workers safety especially in situations where there is risk of contagious infections. There are a number of technologies that can be used in telemedicine, which can help patients adhere better to their medication regimens and manage their diseases better. Telemedicine can also enable the availability of vital parameters of the patient available to the physician with the help of medical devices such as blood pressure, blood glucose, etc management.

Disasters and pandemics pose unique challenges to providing health care. Though telemedicine will not solve them all, it is well suited for scenarios in which medical practitioners can evaluate and manage patients. A telemedicine visit can be conducted without exposing staff to viruses/infections in the times of such outbreaks. Telemedicine practice can prevent the transmission of infectious diseases reducing the risks to both health care workers and patients. Unnecessary and avoidable exposure of the people involved in delivery of healthcare can to be avoided using telemedicine and patients can be screened remotely. It can provide rapid access to medical practitioners who may not be immediately available in person. In addition, it makes available extra working hands to provide physical care at the respective health institutions. Thus, health systems that are invested in telemedicine are well positioned to ensure that patients with Covid-19 kind of issues receive the care they need.

The government is committed to providing equal access to quality care to all and digital health is a critical enabler for the overall transformation of the health system. Hence, mainstreaming telemedicine in health systems will minimize inequity and barriers to access. India's digital health policy advocates use of digital tools for improving the efficiency and outcome of the healthcare system and lays significant focus on the use of telemedicine services, especially in the Health and Wellness Centers at the grassroots level wherein a midlevel provider/health worker can connect the patients to the doctors through technology platforms in providing timely and best possible care. 
However, there has been concern on the practice of telemedicine. Lack of clear guidelines has created significant ambiguity for registered medical professionals, raising doubts on the practice of telemedicine. The 2018 judgement of the Hon'ble High Court of Bombay had created uncertainty about the place and legitimacy of telemedicine because an appropriate framework does not exist.

In India, till now there was no legislation or guidelines on the practice of telemedicine, through video, phone, Internet based platforms (web/chat/apps etc). The existing provisions under the Indian Medical Council Act, 1956, the Indian Medical Council (Professional Conduct, Etiquette and Ethics Regulation 2002), Drugs \&Cosmetics Act, 1940 and Rules 1945, Clinical Establishment (Registration and Regulation) Act, 2010, Information Technology Act, 2000 and the Information Technology (Reasonable Security Practices and Procedures and Sensitive Personal Data or Information) Rules 2011 primarily govern the practice of medicine and information technology. Gaps in legislation and the uncertainty of rules pose a risk for both the doctors and their patients.

There are some countries that have put in legislative measures and some countries, which follow nonlegislative measures such as guidelines to practice telemedicine. In some countries guidelines are treated as professional norms that need to be followed by medical practitioners. We reviewed these other guidelines and consulted to put together these guidelines to enable medical practitioners to practice telemedicine.

Telemedicine will continue to grow and be adopted by more healthcare practitioners and patients in a wide variety of forms, and these practice guidelines will be a key enabler in fostering its growth.

\section{Purpose}

The purpose of these guidelines is to give practical advice to doctors so that all services and models of care used by doctors and health workers are encouraged to consider the use of telemedicine as a part of normal practice. These guidelines will assist the medical practitioner in pursuing a sound course of action to provide effective and safe medical care founded on current information, available resources, and patient needs to ensure patient and provider safety.

These telemedicine guidelines will help realize the full potential of these advancements in technology for health care delivery. It provides norms and protocols relating to physician-patient relationship; issues of liability and negligence; evaluation, management and treatment; informed consent; continuity of care; referrals for emergency services; medical records; privacy and security of the patient records and exchange of information; prescribing; and reimbursement; health education and counseling.

These guidelines will provide information on various aspects of telemedicine including information on technology platforms and tools available to medical practitioners and how to integrate these technologies to provide health care delivery. It also spells out how technology and transmission of voice, data, images and information should be used in conjunction with other clinical standards, protocols, policies and procedures for the provision of care. Where clinically appropriate, telemedicine is a safe, effective and a valuable modality to support patient care.

Like any other technology, the technology used for telemedicine services can be abused. It has some risks, drawbacks and limitations, which can be mitigated through appropriate training, enforcement of standards, protocols and guidelines, 
These guidelines should be used in conjunction with the other national clinical standards, protocols, policies and procedures. 


\section{Telemedicine: Definitions and Applications}

\subsection{DEFINITIONS}

\subsubsection{Definition of Telemedicine}

World Health Organization defines telemedicine as

"The delivery of health-care services, where distance is a critical factor, by all health-care professionals using information and communications technologies for the exchange of valid information for diagnosis, treatment and prevention of disease and injuries, research and evaluation, and the continuing education of health-care workers, with the aim of advancing the health of individuals and communities."

\subsubsection{Definition of Telehealth}

NEJM Catalyst defines telehealth as "The delivery and facilitation of health and health-related services including medical care, provider and patient education, health information services, and selfcare via telecommunications and digital communication technologies."

In general, telemedicine is used to denote clinical service delivered by a Registered medical practitioner while telehealth is a broader term of use of technology for health and health related services including telemedicine.

\subsubsection{Definition of Registered Medical Practitioner (RMP)}

For the purpose of this document a 'Registered Medical Practitioner' is defined as a person who is enrolled in the State Medical Register or the Indian Medical Register under the IMC Act 1956.

\subsection{SCOPE}

Within the broad paradigm of telemedicine, these guidelines will be published under the IMC Act and are for privileged access only. These guidelines are designed to serve as an aid and tool to enable RMPs to effectively leverage Telemedicine to enhance healthcare service and access to all

- The guidelines are meant for RMPs under the IMC Act 1956

- The guidelines cover norms and standards of the RMP to consult patients via telemedicine

- Telemedicine includes all channels of communication with the patient that leverage Information Technology platforms, including Voice, Audio, Text \& Digital Data exchange

\section{EXCLUSIONS:}

The guidelines specifically explicitly exclude the following:

- Specifications for hardware or software, infrastructure building \& maintenance

- Data management systems involved; standards and interoperability

- Use of digital technology to conduct surgical or invasive procedures remotely

- Other aspects of telehealth such as research and evaluation and continuing education of healthcare workers

- Does not provide for consultations outside the jurisdiction of India 
1.3 REGISTERED MEDICAL PRACTITIONERS ARE ENTITLED TO PRACTICE TELEMEDICIN: ALL OF THEM WILL TAKE AN ONLINE COURSE ON PRACTICE OF TELEMEDICINE

1.3.1 A Registered Medical Practitioner is entitled to provide telemedicine consultation to patients from any part of India

1.3.2 RMPs using telemedicine shall uphold the same professional and ethical norms and standards as applicable to traditional in-person care, within the intrinsic limitations of telemedicine

1.3.3 To enable all those RMPs who would want to practice telemedicine get familiar with these Guidelines as well as with the process and limitations of telemedicine practice:

- An online program will be developed and made available by the Board of Governors in supersession of Medical Council of India.

- All registered medical practitioners intending to provide online consultation need to complete a mandatory online course within 3 years of its notification.

- In the interim period, the principles mentioned in these guidelines need to be followed.

- Thereafter, undergoing and qualifying such a course, as prescribed, will be essential prior to practice of telemedicine.

\subsection{TELEMEDICINE APPLICATIONS}

\subsubsection{Tools for Telemedicine}

RMP may use any telemedicine tool suitable for carrying out technology-based patient consultation e.g. telephone, video, devices connected over LAN, WAN, Internet, mobile or landline phones, Chat Platforms like WhatsApp, Facebook Messenger etc., or Mobile App or internet based digital platforms for telemedicine or data transmission systems like Skype/ email/ fax etc.

Irrespective of the tool of communication used, the core principles of telemedicine practice remain the same.

1.4.2 Telemedicine applications can be classified into four basic types, according to the mode of communication, timing of the information transmitted, the purpose of the consultation and the interaction between the individuals involved-be it RMP-to-patient / caregiver, or RMP to RMP.

\subsubsection{According to the Mode of Communication}

- Video (Telemedicine facility, Apps, Video on chat platforms, Skype/Face time etc.)

- Audio (Phone, VOIP, Apps etc.)

- Text Based:

- Telemedicine chat based applications (specialized telemedicine smartphone Apps, Websites, other internet-based systems etc.)

- General messaging/ text/ chat platforms (WhatsApp, Google Hangouts, Facebook Messenger etc.)

- Asynchronous (email/ Fax etc.) 


\subsubsection{According to timing of information transmitted}

\begin{tabular}{|l|}
\hline Real time Video/audio/text interaction \\
\hline Video/audio/text for exchange of relevant \\
information for diagnosis, medication and health \\
education and counseling
\end{tabular}

\begin{tabular}{|l|}
\hline $\begin{array}{c}\text { Asynchronous exchange of relevant } \\
\text { information }\end{array}$ \\
\hline $\begin{array}{l}\text { Transmission of summary of patient } \\
\text { complaints and supplementary data } \\
\text { including images, lab reports and/or } \\
\text { radiological investigations between } \\
\text { stakeholders. Such data can be } \\
\text { forwarded to different parties at any } \\
\text { point of time and thereafter accessed } \\
\text { per convenience/need }\end{array}$ \\
\hline
\end{tabular}

\subsubsection{According to the purpose of the consultation}

For Non-Emergency consult:

\begin{tabular}{|l|}
\hline \multicolumn{1}{|c|}{$\begin{array}{l}\text { First consult with any RMP for } \\
\text { diagnosis/treatment/health } \\
\text { education/ counseling }\end{array}$} \\
\hline $\begin{array}{l}\text { Patients may consult with an RMP for } \\
\text { diagnosis and treatment of her } \\
\text { condition or for health education and } \\
\text { counseling }\end{array}$ \\
\hline
\end{tabular}

Follow-up consult with the same

\section{RMP}

Patients may use this service for follow up consultation on his ongoing treatment with the same RMP who prescribed the treatment in an earlier in-person consult.

Emergency consult for immediate assistance or first aid etc.

- In case alternative care is not present, tele-consultation might be the only way to provide timely care. In such situations, RMPs may provide consultation to their best judgement. Telemedicine services should however be avoided for emergency care when alternative in-person care is available, and telemedicine consultation should be limited to first aid, life-saving measure, counseling and advice on referral.

- In all cases of emergency, the patient must be advised for an in-person interaction with an RMP at the earliest. 


\subsubsection{According to the individuals involved}

\begin{tabular}{|l|}
\hline \multicolumn{1}{c|}{ Patient to RMP } \\
\hline $\begin{array}{l}\text { Telemedicine services may connect patients } \\
\text { to an RMP }\end{array}$ \\
\hline
\end{tabular}

\section{Caregiver to RMP}

Telemedicine services may connect Care givers to an RMP, under certain conditions as detailed in Framework (Section 4)

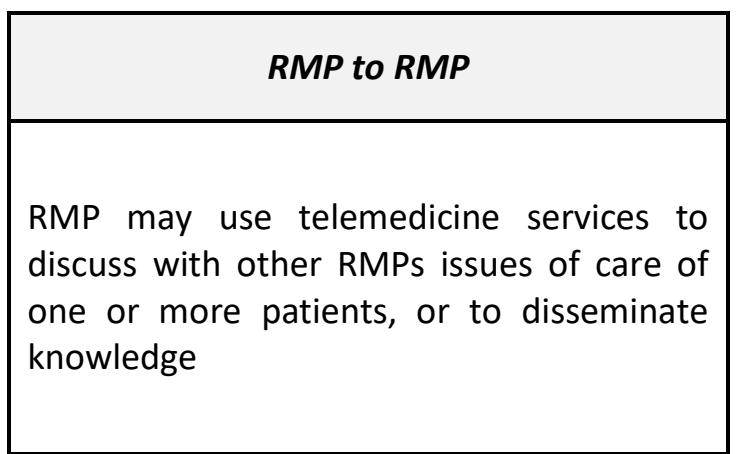

\section{Health worker to RMP}

A Health Worker $^{1}$ can facilitate a consultation session for a patient with an RMP. In doing so, the former can help take history, examine the patient and convey the findings. They can also explain/reinforce the advice given by the RMP to the patient.

\footnotetext{
${ }^{1}$ Nurse, Allied Health Professional, Mid-level health provider, ANM or any other health worker designated by an appropriate authority
} 


\section{Technology Used \& Mode of Communications}

Multiple technologies can be used to deliver telemedicine consultation. There are 3 primary modes: Video, Audio, or Text (chat, messaging, email, fax etc.) Each one of these technology systems has their respective strengths, weaknesses and contexts, in which, they may be appropriate or inadequate to deliver a proper diagnosis.

It is therefore important to understand the strengths, benefits as well as limitations of different technologies. Broadly, though telemedicine consultation provides safety to the RMP from contagious conditions, it cannot replace physical examination that may require palpation, percussion or auscultation; that requires physical touch and feel. Newer technologies may improve this drawback.

\section{STRENGTHS AND LIMITATIONS OF VARIOUS MODES OF COMMUNICATION}

\begin{tabular}{|c|c|c|}
\hline Mode & Strengths & Limitations \\
\hline $\begin{array}{l}\text { VIDEO: } \\
\text { Telemedicine } \\
\text { facility, } \\
\text { Apps, } \\
\text { Video on chat } \\
\text { platforms, } \\
\text { Facetime etc. }\end{array}$ & $\begin{array}{l}\text { - } \text { Closest to an in person-consult, } \\
\text { real time interaction } \\
\text { - Patient identification is easier } \\
\text { - RMP can see the patient and } \\
\text { - } \text { discuss with the caregiver } \\
\text { - } \text { Insual cues can be perceived } \\
\text { carried out }\end{array}$ & $\begin{array}{l}\text { - Is dependent on high quality } \\
\text { internet connection at both ends, } \\
\text { else will lead to a sub optimal } \\
\text { exchange of information } \\
\text { - Since there is a possibility of } \\
\text { abuse/ misuse, ensuring privacy of } \\
\text { patients in video consults is } \\
\text { extremely important }\end{array}$ \\
\hline $\begin{array}{l}\text { AUDIO: } \\
\text { Phone, } \\
\text { VOIP, } \\
\text { Apps etc. }\end{array}$ & $\begin{array}{ll}\text { - } & \text { Convenient and fast } \\
\text { - } & \text { Unlimited reach } \\
\text { - } & \text { Suitable for urgent cases } \\
\text { - } & \text { No separate infrastructure } \\
& \text { required } \\
\text { - } & \text { Privacy ensured } \\
\text { - } & \text { Real-time interaction. }\end{array}$ & $\begin{array}{l}\text { - Non-verbal cues may be missed } \\
\text { - Not suitable for conditions that } \\
\text { require a visual inspection (e.g. } \\
\text { skin, eye or tongue examination), } \\
\text { or physical touch } \\
\text { - Patient identification needs to be } \\
\text { clearer, greater chance of } \\
\text { imposters representing the real } \\
\text { patient }\end{array}$ \\
\hline $\begin{array}{l}\text { TEXT BASED: } \\
\text { Specialized } \\
\text { Chat based } \\
\text { Telemedicine } \\
\text { Smartphone } \\
\text { Apps, SMS, } \\
\text { Websites, }\end{array}$ & $\begin{array}{l}\text { - } \text { Convenient and quick } \\
\text { - Documentation \& Identification } \\
\text { may be an integral feature of the } \\
\text { platform } \\
\text { - Suitable for urgent cases, or } \\
\text { follow-ups, second opinions } \\
\text { provided RMP has enough } \\
\text { context from other sources, }\end{array}$ & $\begin{array}{l}\text { - Besides the visual and physical } \\
\text { touch, text-based interactions also } \\
\text { miss the verbal cues } \\
\text { - Difficult to establish rapport with } \\
\text { the patient. }\end{array}$ \\
\hline
\end{tabular}




\begin{tabular}{|c|c|c|}
\hline $\begin{array}{l}\text { messaging } \\
\text { systems e.g. } \\
\text { WhatsApp, } \\
\text { Google } \\
\text { Hangouts, FB } \\
\text { Messenger }\end{array}$ & $\begin{array}{l}\text { - No separate infrastructure } \\
\text { required, } \\
\text { - Can be real time }\end{array}$ & $\begin{array}{l}\text { - Cannot be sure of identity of the } \\
\text { doctor or the patient }\end{array}$ \\
\hline $\begin{array}{l}\text { ASYNCHRONO } \\
\text { US: } \\
\text { Email } \\
\text { Fax, } \\
\text { recordings etc. }\end{array}$ & $\begin{array}{l}\text { - Convenient and easy to document } \\
\text { - No specific app or download } \\
\text { requirement } \\
\text { - Images, data, reports readily } \\
\text { shared } \\
\text { - No separate infrastructure } \\
\text { required } \\
\text { - More useful when accompanied } \\
\text { with test reports and follow up } \\
\text { and second opinions }\end{array}$ & $\begin{array}{l}\text { - Not a real time interaction, so just } \\
\text { one-way context is available, } \\
\text { relying solely on the articulation by } \\
\text { the patient } \\
\text { - Patient identification is document } \\
\text { based only and difficult to confirm } \\
\text { - Non-verbal cues are missed } \\
\text { - There may be delays because the } \\
\text { Doctor may not see the mail } \\
\text { immediately }\end{array}$ \\
\hline
\end{tabular}




\section{Guidelines for Telemedicine in India}

The professional judgment of a Registered Medical Practitioner should be the guiding principle for all telemedicine consultations: An RMP is well positioned to decide whether a technology-based consultation is sufficient or an in-person review is needed. Practitioner shall exercise proper discretion and not compromise on the quality of care. Seven elements need to be considered before beginning any telemedicine consultation (see panel)

\begin{tabular}{|l|l|}
\hline \multicolumn{2}{|l|}{$\begin{array}{l}\text { Seven Elements to be considered before } \\
\text { any telemedicine consultation }\end{array}$} \\
\hline 1 & Context \\
\hline 2 & Identification of RMP and Patient \\
\hline 3 & Mode of Communication \\
\hline 4 & Consent \\
\hline 5 & Type of Consultation \\
\hline 6 & Patient Evaluation \\
\hline 7 & Patient Management \\
\hline
\end{tabular}

\subsection{TELEMEDICINE SHOULD BE APPROPRIATE AND SUFFICIENT AS PER CONTEXT}

3.1.1 The Registered Medical Practitioners should exercise their professional judgment to decide whether a telemedicine consultation is appropriate in a given situation or an in-person consultation is needed in the interest of the patient. They should consider the mode/technologies available and their adequacy for a diagnosis before choosing to proceed with any health education or counseling or medication. They should be reasonably comfortable that telemedicine is in the patient's interest after taking a holistic view of the given situation.

\subsubsection{Complexity of Patient's health condition}

Every patient/case/medical condition may be different, for example, a new patient may present with a simple complaint such as headache while a known patient of Diabetes may consult for a followup with emergencies such as Diabetic Ketoacidosis. The RMP shall uphold the same standard of care as in an in-person consultation but within the intrinsic limits of telemedicine.

\subsection{IDENTIFICATION OF THE REGISTERED MEDICAL PRACTITIONER AND THE PATIENT IS REQUIRED}

3.2.1 Telemedicine consultation is should not be anonymous: both patient and the RMP need to know each other's identity.

3.2.2 An RMP should verify and confirm patient's identity by name, age, address, email ID, phone number, registered ID or any other identification as may be deemed to be appropriate. The RMP should ensure that there is a mechanism for a patient to verify the credentials and contact details of the RMP. 
3.2.3 For issuing a prescription, the RMP needs to explicitly ask the age of the patient, and if there is any doubt, seek age proof. Where the patient is a minor, after confirming the age, tele consultation would be allowed only if the minor is consulting along-with an adult whose identity needs to be ascertained.

3.2.4 An RMP should begin the consultation by informing the patient about his/her name and qualifications.

3.2.5 Every RMP shall display the registration number accorded to him/her by the State Medical Council/MCl, on prescriptions, website, electronic communication (WhatsApp/ email etc.) and receipts etc. given to his/her patients

\subsection{MODE OF TELEMEDICINE}

3.3.1 Multiple technologies can be used to deliver telemedicine consultations. All these technology systems have their respective strengths, weaknesses and contexts in which they may be appropriate or inadequate in order to deliver proper care.

3.3.2 Primarily there are 3 modes: Video, Audio or Text (chat, images, messaging, email, fax etc.). Their strengths, limitations and appropriateness as detailed in Section 2 need to be considered by the RMP.

3.3.3 There may be situations where in order to reach a diagnosis and to understand the context better; a real-time consultation may be preferable over an asynchronous exchange of information. Similarly, there would be conditions where an RMP could require hearing the patient speak, therefore, a voice interaction may be preferred than an email or text for a diagnosis. There are also situations where the RMP needs to visually examine the patient and make a diagnosis. In such a case, the RMP could recommend a video consultation. Considering the situation, using his/her best judgment, an RMP may decide the best technology to use to diagnose and treat.

\subsection{PATIENT CONSENT}

Patient consent is necessary for any telemedicine consultation. The consent can be Implied or explicit depending on the following situations:

3.4.1 If, the patient initiates the telemedicine consultation, then the consent is implied ${ }^{2}$.

3.4.2 An Explicit patient consent is needed if:

A Health worker, RMP or a Caregiver initiates a Telemedicine consultation.

${ }^{2}$ Implied Consent: In an in-person consultation, it is assumed the patient has consented to the consult by his/her actions. When the patient walks in an OPD, the consent for the consultation is taken as implied. Like an in-person consultation, for most of the tele-consultations the consent can be assumed to be implied because the patient has initiated the consultation. 
3.4.3 An Explicit consent can be recorded in any form. Patient can send an email, text or audio/video message. Patient can state his/her intent on phone/video to the RMP (e.g. "Yes, I consent to avail consultation via telemedicine" or any such communication in simple words). The RMP must record this in his patient records.

\subsection{EXCHANGE OF INFORMATION FOR PATIENT EVALUATION}

RMPs must make all efforts to gather sufficient medical information about the patient's condition before making any professional judgment.

\subsubsection{Patient's Information}

- An RMP would use his/her professional discretion to gather the type and extent of patient information (history/examination findings/Investigation reports/past records etc.) required to be able to exercise proper clinical judgement.

- This information can be supplemented through conversation with a healthcare worker/provider and by any information supported by technology-based tools.

- If the RMP feels that the information received is inadequate, then he/she can request for additional information from the patient. This information may be shared in real time or shared later via email/text, as per the nature of such information. For example, an RMP may advise some laboratory or/and radiological tests to the patient. In such instances, the consult may be considered paused and can be resumed at the rescheduled time. An RMP may provide health education as appropriate at any time.

- Telemedicine has its own set of limitations for adequate examination. If a physical examination is critical information for consultation, RMP should not proceed until a physical examination can be arranged through an in-person consult. Wherever necessary, depending on professional judgement of the RMP, he/she shall recommend:

- Video consultation

- Examination by another RMP/ Health Worker ;

- In-person consultation

- The information required may vary from one RMP to another based on his/her professional experience and discretion and for different medical conditions based on the defined clinical standards and standard treatment guidelines.

- RMP shall maintain all patient records including case history, investigation reports, images, etc. as appropriate. 


\subsection{TYPES OF CONSULTATION: FIRST CONSULT/ FOLLOW-UP CONSULT}

There are two types of patient consultations, namely, first consult and the follow-up consult.

An RMP may have only a limited understanding of the patient seeking teleconsultation for the first time, when there have been no prior in-person consultation. However, if the first consult happens to be via video, RMP can make a much better judgment and hence can provide much better advice including additional medicines, if indicated.

On the other hand, if a patient has been seen in-person earlier by the RMP, then it is possible to be more comprehensive in managing the patient.

\subsubsection{First Consult means}

- The patient is consulting with the RMP for the first time; or

- The patient has consulted with the RMP earlier, but more than 6 months have lapsed since the previous consultation; or

- The patient has consulted with the RMP earlier, but for a different health condition

\subsubsection{Follow-Up Consult(s) means}

- The patient is consulting with the same RMP within 6 months of his/her previous inperson consultation and this is for continuation of care of the same health condition. However,

it will not be considered a follow up if:

- There are new symptoms that are not in the spectrum of the same health condition; and/or

- RMP does not recall the context of previous treatment and advice

\subsection{PATIENT MANAGEMENT: HEALTH EDUCATION, COUNSELING \& MEDICATION}

3.7.1 If the condition can be appropriately managed via telemedicine, based on the type of consultation, then the RMP may proceed with a professional judgement to:

- Provide Health Education as appropriate in the case; and/or

- Provide Counseling related to specific clinical condition; and/or

- Prescribe Medicines

3.7.2 Health Education: An RMP may impart health promotion and disease prevention messages. These could be related to diet, physical activity, cessation of smoking, contagious infections and so on. Likewise, he/ she may give advice on immunizations, exercises, hygiene practices, mosquito control etc 
3.7.3 Counseling: This is specific advice given to patients and it may, for instance, include food restrictions, do's and don't's for a patient on anticancer drugs, proper use of a hearing aid, home physiotherapy, etc to mitigate the underlying condition. This may also include advice for new investigations that need to be carried out before the next consult.

\subsubsection{Prescribing Medicines}

Prescribing medications, via telemedicine consultation is at the professional discretion of the RMP. It entails the same professional accountability as in the traditional in-person consult. If a medical condition requires a particular protocol to diagnose and prescribe as in a case of in-person consult then same prevailing principle will be applicable to a telemedicine consult.

RMP may prescribe medicines via telemedicine ONLY when RMP is satisfied that he/ she has gathered adequate and relevant information about the patient's medical condition and prescribed medicines are in the best interest of the patient.

Prescribing Medicines without an appropriate diagnosis/provisional diagnosis will amount to a professional misconduct

\section{Specific Restrictions}

There are certain limitations on prescribing medicines on consult via telemedicine depending upon the type of consultation and mode of consultation. The categories of medicines that can be prescribed via tele-consultation will be as notified in consultation with the Central Government from time to time.

The categories of medicines that can be prescribed are listed below:

- List O: It will comprise those medicines which are safe to be prescribed through any mode of tele-consultation. In essence they would comprise of

- Medicines which are used for common conditions and are often available 'over the counter'. For instance, these medicines would include, paracetamol, ORS solutions, cough lozenges etc

- Medicines that may be deemed necessary during public health emergencies.

- List A: These medications are those which can be prescribed during the first consult which is a video consultation and are being re-prescribed for re-fill, in case of follow-up.

- This would be an inclusion list, containing relatively safe medicines with low potential for abuse Is a list of medication which RMP can prescribe in a patient who is undergoing follow-up consult, as a refill. 
- List B: Is a list of medication which RMP can prescribe in a patient who is undergoing follow-up consultation in addition to those which have been prescribed during in-person consult for the same medical condition.

- Prohibited List: An RMP providing consultation via telemedicine cannot prescribe medicines in this list. These medicine have a high potential of abuse and could harm the patient or the society at large if used improperly

- Medicines listed in Schedule $\boldsymbol{X}$ of Drug and Cosmetic Act and Rules or any Narcotic and Psychotropic substance listed in the Narcotic Drugs and Psychotropic Substances, Act, 1985

The drugs in the above mentioned list is summarized in Annexure 1

\subsubsection{Issue a Prescription and Transmit}

- If the RMP has prescribed medicines, RMP shall issue a prescription as per the Indian Medical Council (Professional Conduct, Etiquette and Ethics) Regulations and shall not contravene the provisions of the Drugs and Cosmetics Act and Rules. A sample format is suggested in Annexure 2

- RMP shall provide photo, scan, digital copy of a signed prescription or e-Prescription to the patient via email or any messaging platform

- In case the RMP is transmitting the prescription directly to a pharmacy, he/ she must ensure explicit consent of the patient that entitles him/her to get the medicines dispensed from any pharmacy of his/ her choice 
Table: Matrix of the permissible drug lists based on the type and mode of consultation

\begin{tabular}{|c|c|c|c|}
\hline List Group & $\begin{array}{l}\text { Mode of Consultation } \\
\text { [Video/Audio/Text] }\end{array}$ & $\begin{array}{c}\text { Nature of Consultation } \\
\text { [First-consultation/ } \\
\text { Follow-up] }\end{array}$ & List of Medicines \\
\hline 0 & Any & Any & List $\mathrm{O}^{1}$ \\
\hline A & Video & $\begin{array}{l}\text { First Consultation } \\
\text { Follow-up, for } \\
\text { continuation of } \\
\text { medications } \\
\end{array}$ & List $A^{2}$ \\
\hline B & Any & Follow-up & List $B^{3}$ \\
\hline Prohibited & Not to be prescribed & Not to be prescribed & $\begin{array}{l}\text { Schedule X of Drug and } \\
\text { Cosmetic Act and Rules } \\
\text { or any Narcotic and } \\
\text { Psychotropic substance } \\
\text { listed in the Narcotic } \\
\text { Drugs and Psychotropic } \\
\text { Substances, Act, } 1985^{4}\end{array}$ \\
\hline 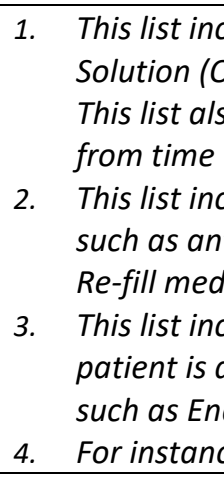 & $\begin{array}{l}\text { mmonly used 'over-the-cou } \\
\text { kets, Antacids etc. } \\
\text { es medicines that may be d } \\
\text { ually prescribed medication } \\
\text { medications for Tinea Cruri } \\
\text { for chronic diseases such as } \\
\text { dd-on' medications which a } \\
\text { n Atenolol for hypertension } \\
\text { Cancer drugs; Narcotics suc }\end{array}$ & $\begin{array}{l}\text { er' medications such as Parac } \\
\text { ned necessary during emerge } \\
\text { or which diagnosis is possible } \\
\text { iprofloxacillin eye drops for } \\
\text { abetes, Hypertension, Asthm } \\
\text { used to optimize an existing } \\
\text { d the blood pressure is not ca } \\
\text { s Morphine, Codeine etc }\end{array}$ & $\begin{array}{l}\text { tamol, Oral Rehydration } \\
\text { cies and would be notified } \\
\text { nly by video consultation } \\
\text { njunctivitis etc. and } \\
\text { etc } \\
\text { ndition. For instance, if the } \\
\text { trolled, an ACE inhibitor }\end{array}$ \\
\hline
\end{tabular}




\subsubsection{MEDICAL ETHICS, DATA PRIVACY \& CONFIDENTIAILITY ${ }^{3}$}

3.7.1.1 Principles of medical ethics, including professional norms for protecting patient privacy and confidentiality as per IMC Act shall be binding and must be upheld and practiced.

3.7.1.2 Registered Medical Practitioner would be required to fully abide by Indian Medical Council (Professional conduct, Etiquette and Ethics) Regulations, 2002 and with the relevant provisions of the IT Act, Data protection and privacy laws or any applicable rules notified from time to time for protecting patient privacy and confidentiality and regarding the handling and transfer of such personal information regarding the patient. This shall be binding and must be upheld and practiced.

3.7.1.3 Registered Medical Practitioners will not be held responsible for breach of confidentiality if there is a reasonable evidence to believe that patient's privacy and confidentiality has been compromised by a technology breach or by a person other than RMP. The RMPs should ensure that reasonable degree of care undertaken during hiring such services.

\subsubsection{Misconduct}

It is specifically noted that in addition to all general requirements under the $\mathrm{MCl}$ Act for professional conduct, ethics etc, while using telemedicine all actions that wilfully compromise patient care or privacy and confidentiality, or violate any prevailing law are explicitly not permissible.

Some examples of actions that are not permissible:

- RMPs insisting on Telemedicine, when the patient is willing to travel to a facility and/or requests an in-person consultation

- RMPs misusing patient images and data, especially private and sensitive in nature (e.g. RMP uploads an explicit picture of patient on social media etc)

- RMPs who use telemedicine to prescribe medicines from the specific restricted list

- RMPs are not permitted to solicit patients for telemedicine through any advertisements or inducements

3.7.1.5 Penalties: As per IMC Act, ethics and other prevailing laws.

\footnotetext{
${ }^{3}$ It is the responsibility of the RMP to be cognizant of the current Data Protection and Privacy laws. RMP shall not breach the patient's confidentiality akin to an in-person consultation. For example: If the RMP is planning to create virtual support group for disseminating health education for patients suffering from a particular disease condition then he/she shall be wary of the patient's willingness and not violate patient's privacy and confidentiality by adding them to the group without their consent.
} 


\subsubsection{MAINTAIN DIGITAL TRAIL/ DOCUMENTATION OF CONSULTATION}

It is incumbent on RMP to maintain the following records/ documents for the period as prescribed from time to time:

3.7.2.1 Log or record of Telemedicine interaction (e.g. Phone logs, email records, chat/ text record, video interaction logs etc.).

3.7.2.2 Patient records, reports, documents, images, diagnostics, data etc. (Digital or non-Digital) utilized in the telemedicine consultation should be retained by the RMP.

3.7.2.3 Specifically, in case a prescription is shared with the patient, the RMP is required to maintain the prescription records as required for in-person consultations.

\subsubsection{Fee for Telemedicine Consultation}

3.7.3.1 Telemedicine consultations should be treated the same way as in-person consultations from a fee perspective: RMP may charge an appropriate fee for the Telemedicine consultation provided.

3.7.3.2 An RMP should also give a receipt/invoice for the fee charged for providing telemedicinebased consultation. 


\section{Framework for Telemedicine}

This section lays out the framework for practicing telemedicine in 5 scenarios:

1. Patient to Registered Medical Practitioner

2. Caregiver to Registered Medical Practitioner

3. Health Worker to Registered Medical Practitioner

4. Registered Medical Practitioner to Registered Medical Practitioner

5. Emergency Situations

\section{Essential Principles:}

- The professional judgement of a Registered Medical Practitioner should be the guiding principle: an RMP is well positioned to decide whether a technology-based consultation is sufficient, or an in-person review is needed. Practitioner shall exercise proper discretion and not compromise on the quality of care

- Same principles apply irrespective of the mode (video, audio, text) used for a telemedicine consultation. However, the patient management and treatment can be different depending on the mode of communication used.

- RMP should exercise his/her professional discretion for the mode of communication depending on the type of medical condition. If a case requires a video consultation for examination, RMP should explicitly ask for it

- The RMP can choose not to proceed with the consultation at any time. At any step, the RMP may refer or request for an in-person consultation

- At any stage, the patient has the right to choose to discontinue the teleconsultation

\subsection{CONSULTATION BETWEEN PATIENT AND REGISTERED MEDICAL PRACTITIONER}

Specifically, this section details with the key elements of the process of teleconsultation to be used in the First consults and Follow up consults when a patient consults with an RMP.

In these 2 situations, the patient initiates telemedicine consultation and thereby consent is implied

\subsubsection{First Consult: Patient to Registered Medical Practitioner}

\subsubsection{First Consult means}

1. The patient is consulting with the RMP for the first time; or

2. The patient has consulted with the RMP earlier, but more than 6 months have lapsed since the previous consultation; or

3. The patient has consulted with the RMP earlier, but for a different health condition 


\subsubsection{Tele-Consultation Process}

The flow of the process is summarized in the Figure 1 and the steps are detailed below.

\section{Start of a Telemedicine Consultation for First Consult}

$\circ \quad$ The telemedicine consultation is initiated by the patient (For example, a patient may do an audio or video call with a RMP or send an email or text with a health query)

- RMP accepts to undertake the consultation

\section{Patient identification and consent}

- RMP should confirm patient identity to his/her satisfaction by asking patient's name, age, address, email ID, phone number or any other identification that may be reasonable

- Telemedicine consultation should be initiated by the patient and thereby consent is implied

\section{Quick assessment:}

- The patient's condition needs to be quickly assessed by the RMP based on available inputs and RMP uses his professional discretion if emergency care is needed, to decide if emergency care is needed.

- If the condition of the patient merits emergency intervention, then advice for first aid/ immediate relief is provided and guidance is provided for referral, as appropriate.

If the condition does not merit an emergency intervention, the following steps are undertaken:

\section{Exchange of Information for Patient Evaluation}

- The RMP may ask the patient to provide relevant information (complaints, information about any other consults for the same problem, available investigation and medication details, if any). The patient shall be responsible for accuracy of information shared by him/her with the RMP.

- If the RMP feels that the information provided at this stage is inadequate, then he/she shall request for additional information from the patient. This information may be shared in real time or shared later via email/text, as per the nature of such information. The consultation may be resumed at a rescheduled time after receipt of the additional information (this may include some laboratory or radiological tests). In the meantime, the RMP may provide health advice as appropriate.

- If the RMP is satisfied that he/she has adequate patient information for offering a professional opinion, then he/she shall exercise one's professional judgment for its suitability for management via telemedicine.

- If the situation is NOT appropriate for further telemedicine consultation, then the RMP should provide Health advice/ Education as appropriate; and/or refer for in-person consultation. 


\section{Patient Management}

If the condition can be appropriately managed via telemedicine, then the RMP may take a professional judgement to either:

- Provide Health Education as appropriate in the case; and/or

- Provide Counseling related to specific clinical condition, including advice related to new investigations that need to be carried out before next consult; and/or

- Provide specific treatment by prescribing medicines as in List $\mathrm{O}$ (which are over the counter drugs or others as notified). Additional medicines (as per List A) can also be prescribed if the ongoing tele-consultation is on video.

\subsubsection{Follow-up Consult: Patient to Registered Medical Practitioner}

In a follow-up consultation, since the RMP-patient interaction has already taken place for the specific medical condition under follow-up, there is already an understanding of the context, with availability of previous records. This allows a more definitive and secure interaction between the RMP and the patient.

\subsubsection{Follow-Up Consult means}

The patient is consulting with the RMP within 6 months of his/her previous in-person, and this consultation is for continuation of care of the same health condition. Follow-up can be in situations of a chronic disease or a treatment (e.g. renewal or change in medications) when a face-to-face consultation is not necessary. Examples of such chronic diseases are: asthma, diabetes, hypertension and epilepsy etc

\subsubsection{Tele-Consultation Process}

The flow of the process is summarized in Figure 2 and the steps are detailed below:

\section{Start of a Telemedicine Consultation for Follow Up}

- Patient may initiate a follow up consult with a RMP for continuation of his/her ongoing treatment or for a new complaint or complication arising during the course of the ongoing treatment using any mode of communication. For e.g., the patient may do an audio or video call with a RMP or send him/her an email or text message with a specific health query

- RMP accepts to undertake the consultation

\section{Patient identification and consent}


- RMP should be reasonably convinced that he/she is communicating with the known patient, for e.g. if the patient is communicating with RMP through the registered phone number or registered email id

- If there is any doubt RMP can request the patient to reinitiate the conversation from a registered phone number or email id or should confirm patient identity to his/her satisfaction by asking patient's name, age, address, email ID or phone number. [Details in the section 3.2]

- Patient initiates the Telemedicine consultation and thereby consent is implied

\section{Quick Assessment for Emergency Condition}

- If the patient presents with a complaint which the RMP identifies as an emergency condition necessitating urgent care, the RMP would then advice for first aid to provide immediate relief and guide for referral of the patient, as deemed necessary.

\section{In case of routine follow-up consultation, the following would be undertaken:}

- If the RMP has access to previous records of the patient, he/ she may proceed with continuation of care.

- RMP shall apply his/her professional discretion for type of consultation based on the adequacy of patient information (history/examination findings/Investigation reports/past records).

- If the RMP needs additional information, he/ she should seek the information before proceeding and resume tele-consultation for later point in time.

\section{Patient Management}

- If RMP is satisfied that he/she has access to adequate patient information and if the condition can be appropriately managed by tele-consultation, he/she would go ahead with the tele-management of the patient.

- If the follow-up is for continuation of care, then the RMP may take a professional judgement to either:

- Provide health education as appropriate in the case; or

- Provide counseling related to specific clinical condition including advice related to new investigations that need to be carried out before next consult;

- And/or Prescribe Medications. The medications could be either of the below:

- If the follow up is for continuation of care for the same medical condition, the RMP would re-prescribe original set of medications for a refill (List A of medications, which has been previously prescribed for the patient). 
- If the RMP considers addition of a new drug, as an 'add-on' medication to optimize the underlying medical condition, then the RMP can prescribe medications listed under List $B$.

- If the follow-up consult is for a new minor ailment necessitating only 'over the counter' medications or those notified for this purpose, medications under List $\mathrm{O}$ can be prescribed.

- If the follow-up consult reveals new symptom pertaining to a different spectrum of disease, then the RMP would proceed with the condition as enunciated in the scenario for a first-time consultation (4.1.1).

\subsection{CONSULTATION BETWEEN PATIENT AND RMP THROUGH A CAREGIVER}

4.2.1 For the purpose of these guidelines "Caregiver" could be a family member, or any person authorized by the patient to represent the patient.

4.2.2 There could be two possible settings:

1. Patient is present with the Caregiver during the consultation.

2. Patient is not present with the Caregiver. This may be the case in the following:

2a. Patient is a minor (aged 16 or less) or the patient is incapacitated, for example, in medical conditions like dementia or physical disability etc. The care giver is deemed to be authorized to consult on behalf of the patient.

2b. Caregiver has a formal authorization or a verified document establishing his relationship with the patient and/or has been verified by the patient in a previous in-person consult (explicit consult).

In all of the above, the consult shall proceed as in the case of RMP and the patient (first or follow up consult, vide 4.1) 


\section{CONSULTATION BETWEEN HEALTH WORKER AND RMP}

For the purpose of these guidelines, "Health worker" could be a Nurse, Allied Health Professional, MidLevel Health Practitioner, ANM or any other health worker designated by an appropriate authority

\section{Proposed Set up}

- This sub section will cover interaction between a Health Worker seeking consultation for a patient in a public or private health facility.

$0 \quad$ In a public health facility, the mid-level health practitioner at a Sub-center or Health and wellness center can initiate and coordinate the telemedicine consultation for the patient with a RMP at a higher center at district or State or National level. Health and Wellness centers are an integral part of comprehensive primary health care.

- This setting will also include health camps, home visits, mobile medical units or any community-based interaction.

\section{Tele-Consultation Process}

The flow of the process is summarized in Figure 3 and the steps are detailed below:

\section{Start of a Telemedicine Consultation through a Health Worker/RMP}

- The premise of this consultation is that a patient has been seen by the Health worker

○ In the judgment of the health worker, a tele-consultation with a RMP is required

- Health Worker should obtain the patient's informed consent

- Health worker should explain potential use and limitations of a telemedicine consultation

- $\mathrm{He} / \mathrm{she}$ should also confirm patient identity by asking patient's name, age, address, email ID, phone number or any other identification that may be reasonable

- Health Worker initiates and facilitates the telemedicine consultation.

\section{Patient Identification (by RMP)}

- RMP should confirm patient identity to his/her satisfaction by asking patient's name, age, address, email ID, phone number or any other identification that may be reasonable

- RMP should also make their identity known to the patient

\section{Patient Consent (by RMP):}

○ RMP should confirm the patient's consent to continue the consultation 


\section{In case of Emergency,}

- The Health Worker would urgently communicate about the underlying medical condition of the patient to the RMP.

- If based on information provided, if the RMP identifies it as an emergency condition necessitating urgent care, he/she should advice for first aid to be provided by the Health Worker for immediate relief and guide for referral of the patient, as deemed necessary.

In case, the condition is not an emergency, the following steps would be taken:

\section{Exchange of Information for Patient Evaluation (by RMP)}

- The Health Worker must give a detailed explanation of their health problems to the RMP which can be supplemented by additional information by the patient, if required.

- The RMP shall apply his professional discretion for type and extent of patient information (history/examination findings/Investigation reports/past records) required to be able to exercise proper clinical judgement.

- If the RMP feels that the information provided is inadequate, then he/she shall request for additional information. This information may be shared in real time or shared later via email/text, as per the nature of such information. For e.g., RMP may advice some laboratory or/and radiological tests for the patient. For such instances, the consult may be considered paused and can be resumed at the rescheduled time. RMP may provide health education as appropriate at any time.

\section{Patient Management}

- Once the RMP is satisfied that the available patient information is adequate and that the case is appropriate for management via telemedicine, then he/she would proceed with the management. Health worker should document the same in his/her records.

- The RMP may take a professional judgement to either:

- Provide health education as appropriate in the case,

- Provide counseling related to specific clinical condition including advice related to new investigations that need to be carried out before next consult;

- And/or prescribe medications.

- as prescribed for use in guidelines from time to time for a particular cadre of Health Workers.

\subsection{Role of Health Worker:}

In all cases of emergency, the Health Worker must seek measures for immediate relief and first-aid from the RMP who is being tele-consulted. Health worker must provide the immediate relief/first aid as advised by the RMP and facilitate the referral of the patient for appropriate care. The Health Worker must ensure that patient is advised for an in-person interaction with an RMP, at the earliest. 
For patients who can be suitably managed via telemedicine, the Health Worker plays a vital role of

- Reinforcing the health education and counseling provided by the RMP

- Providing the medicine prescribed by the RMP and providing patient counseling on his/her treatment.

\subsection{REGISTERED MEDICAL PRACTITIONER TO ANOTHER RMP/ SPECIALIST}

- Registered Medical Practitioner might use telemedicine services to consult with another RMP or a specialist for a patient under his/her care. Such consultations can be initiated by a RMP on his/her professional judgement.

- The RMP asking for another RMP's advice remains the treating RMP and shall be responsible for treatment and other recommendations given to the patient.

- It is acknowledged that many medical specialties like radiology, pathology, ophthalmology, cardiology, dermatology etc. may be at advanced stages of adoption of technology for exchange of information or some may be at early stage. Guidelines support and encourage interaction between RMPs/ specialists using information technology for diagnosis, management and prevention of disease.

- Tele-radiology is the ability to send radiographic images ( $x$-rays, CT, MRI, PET/CT, SPECT/CT, MG, Ultrasound) from one location to another.

- Tele-pathology is use of technology to transfer image-rich pathology data between distant locations for the purposes of diagnosis, education, and research.

- Tele-ophthalmology access to eye specialists for patients in remote areas, ophthalmic disease screening, diagnosis and monitoring.

\subsection{EMERGENCY SITUATIONS}

In all telemedicine consultations, as per the judgment of the RMP, if it is an emergency situation, the goal and objective should be to provide in-person care at the soonest. However critical steps could be life-saving and guidance and counseling could be critical. For example, in cases involving trauma, right advice and guidance around maintaining the neck position might protect the spine in some cases. The guidelines are designed to provide a balanced approach in such conditions. The RMP, based on his/ her professional discretion may

- Advise first aid

- Counseling

○ Facilitate referral

In all cases of emergency, the patient MUST be advised for an in-person interaction with a Registered Medical Practitioner at the earliest 


\section{Guidelines for Technology Platforms enabling Telemedicine}

This specifically covers those technology platforms which work across a network of Registered medical practitioners and enable patients to consult with RMPs through the platform

5.1 Technology platforms (mobile apps, websites etc.) providing telemedicine services to consumers shall be obligated to ensure that the consumers are consulting with Registered medical practitioners duly registered with national medical councils or respective state medical council and comply with relevant provisions

5.2 Technology Platforms shall conduct their due diligence before listing any RMP on its online portal. Platform must provide the name, qualification and registration number, contact details of every RMP listed on the platform

5.3 In the event some non-compliance is noted, the technology platform shall be required to report the same to $\mathrm{BoG}$, in supersession to $\mathrm{MCl}$ who may take appropriate action

5.4 Technology platforms based on Artificial Intelligence/Machine Learning are not allowed to counsel the patients or prescribe any medicines to a patient. Only a RMP is entitled to counsel or prescribe and has to directly communicate with the patient in this regard. While new technologies such as Artificial Intelligence, Internet of Things, advanced data science-based decision support systems etc. could assist and support a RMP on patient evaluation, diagnosis or management, the final prescription or counseling has to be directly delivered by the RMP

5.6 Technology Platform must ensure that there is a proper mechanism in place to address any queries or grievances that the end-customer may have

5.7 In case any specific technology platform is found in violation, $\mathrm{BoG}, \mathrm{MCl}$ may designate the technology platform as blacklisted, and no RMP may then use that platform to provide telemedicine 


\section{Special responsibilities of Board of Governors in supersession to Medical Council of India (BoG-MCl)}

6.1 Any of the drug-lists contained in Telemedicine Practice Guidelines can be modified by the Board of Governors in super-session of the Medical Council of India/Medical Council of India from time to time, as required.

6.2 The Board of Governors in super-session of the Medical Council of India may issue necessary directions or advisories or clarifications in regard to these Guidelines, as required.

6.3 The Telemedicine Practice Guidelines can be amended from time to time in larger public interest with the prior approval of Central Government [Ministry of Health and Family Welfare, Government of India]. 
Flow charts 


\section{First Consult:}

Patient and Registered Medical Practitioner (RMP)

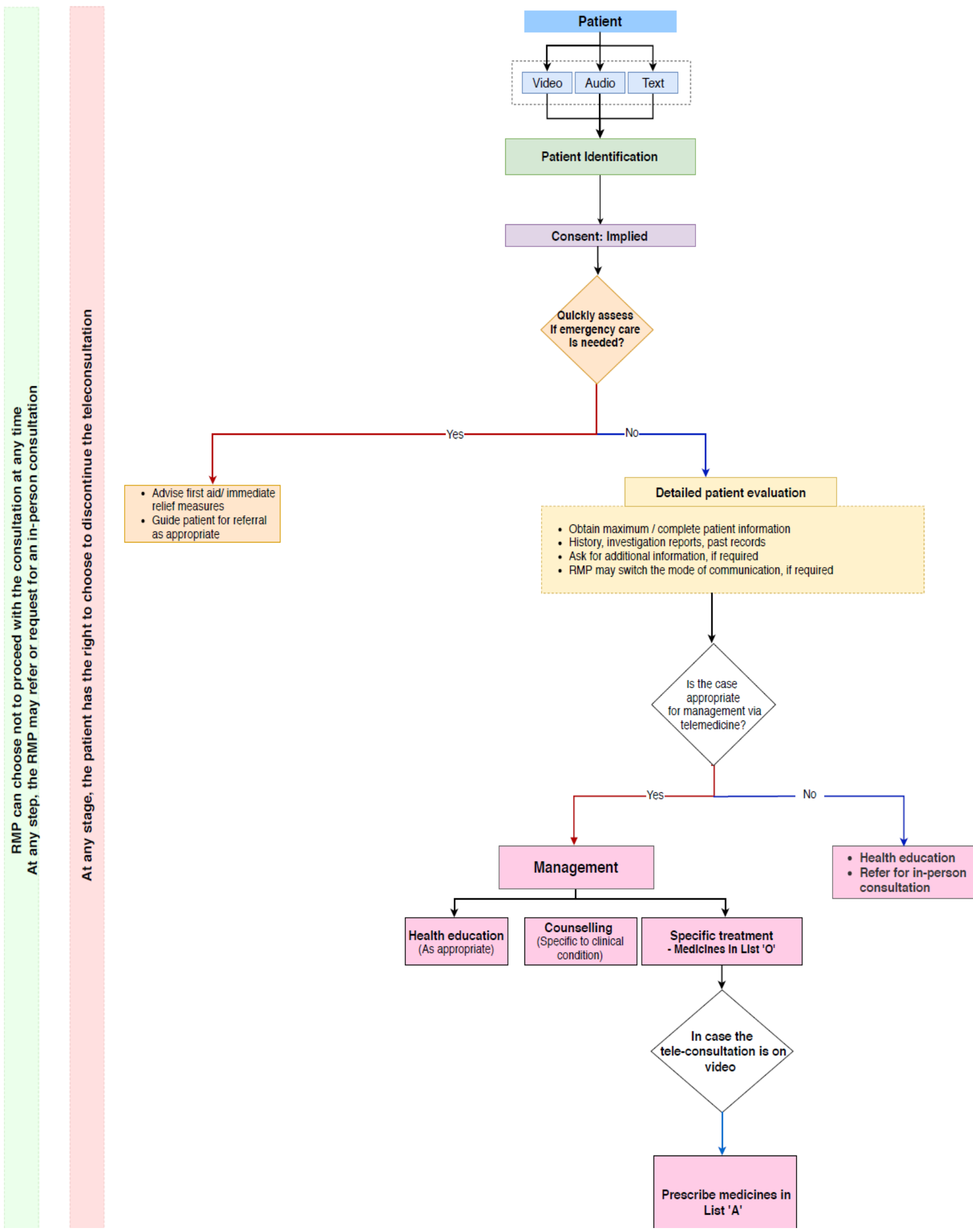


Follow up Consult:

Patient and Registered Medical Practitioner (RMP)
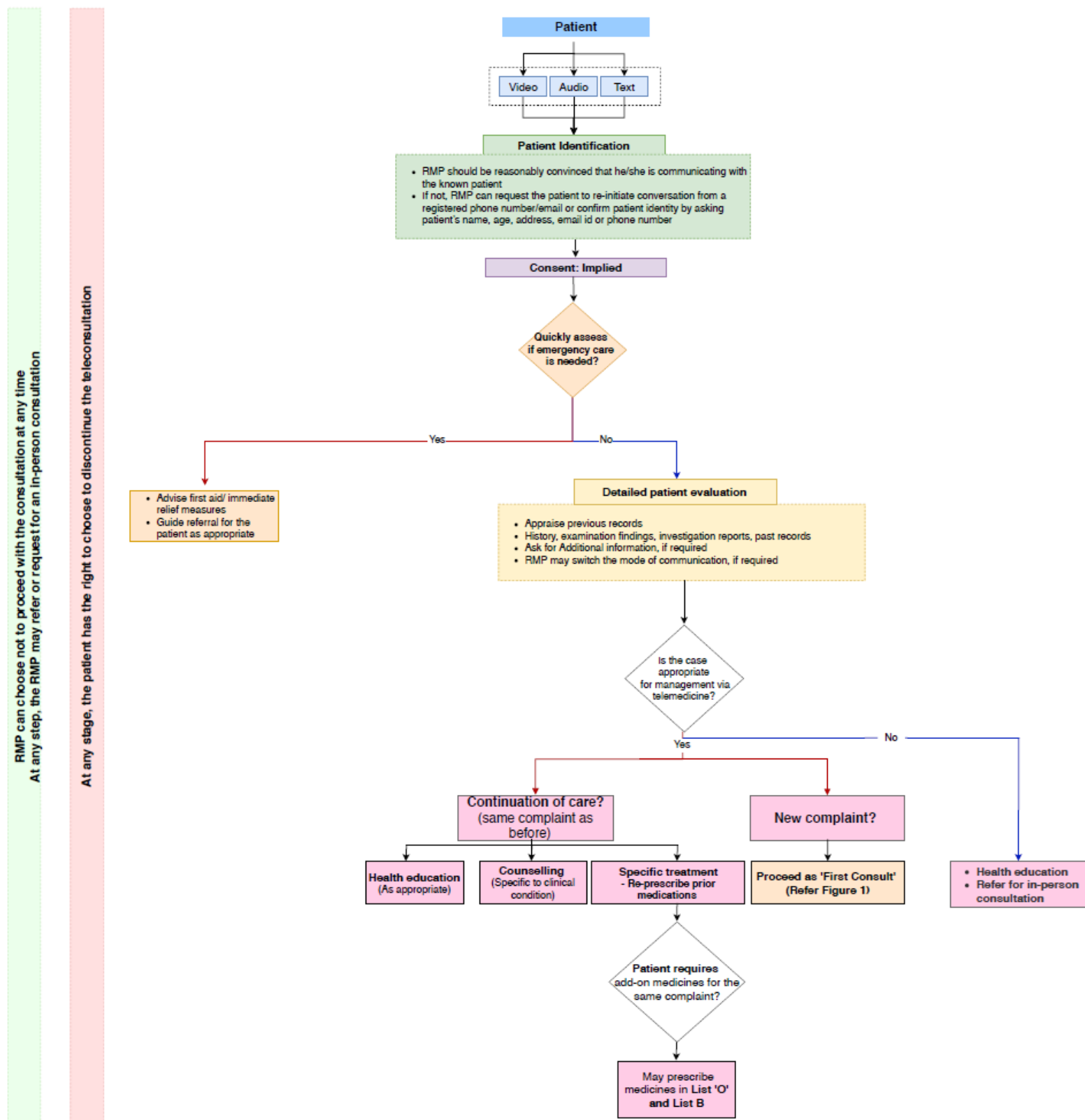

Figure 2: Flow Chart for teleconsultation on follow-up Consult 
This page is intentionally left blank 


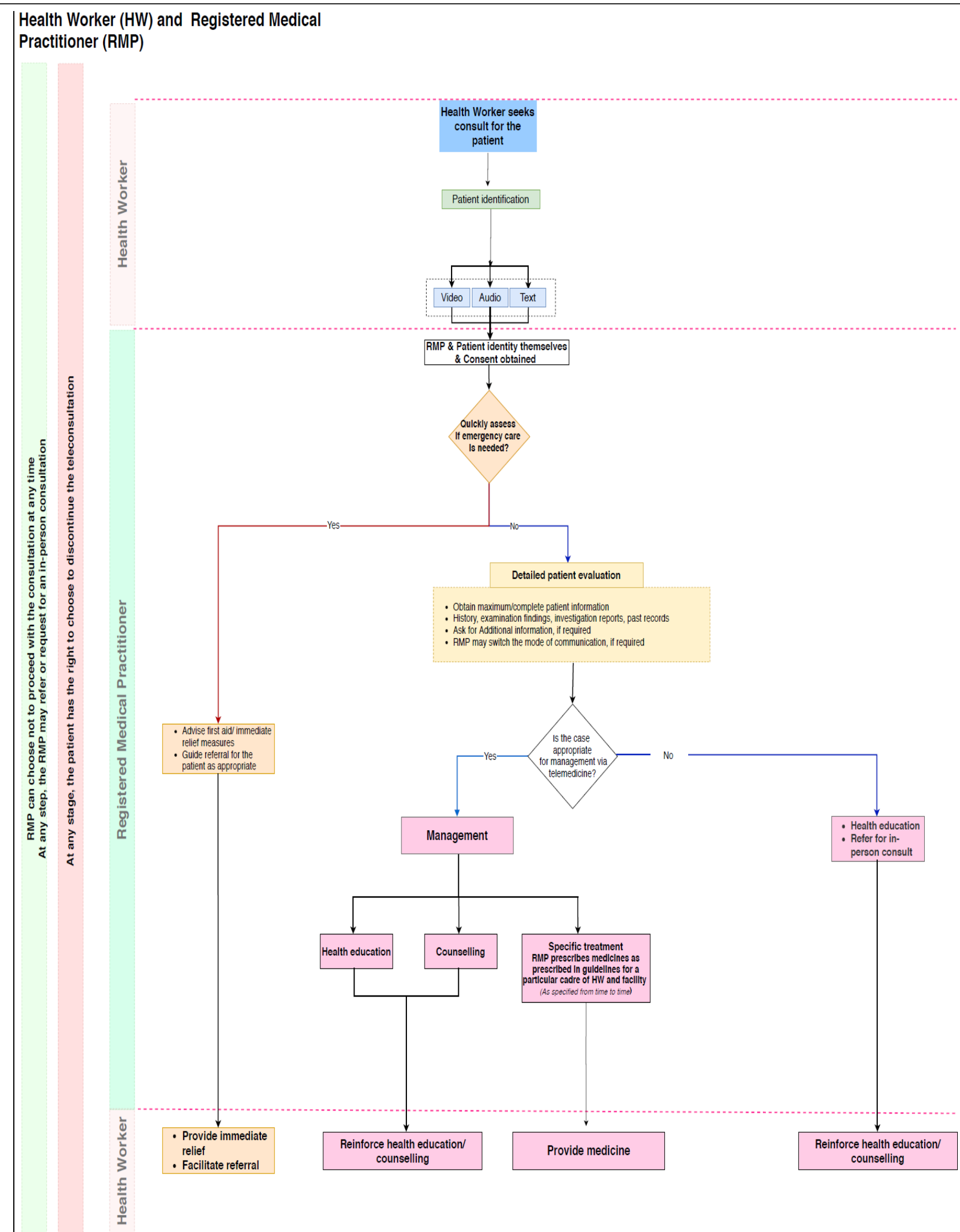

Figure 3: Flow chart for a teleconsultation between a Health Worker (HW) and a Registered Medical Practitioner 
This page is intentionally left blank 
Annexures 
List 0

- Common over-the counter medications such as
- Antipyretics: Paracetamol
- Cough Supplements: Lozenges,
- Cough/ Common-cold medications (such as combinations of Acetylcysteine, Ammonium Chloride, Guaifensen, Ambroxol, Bromhexene, Dextromethorphan)
- ORS Packets
- Syrup Zinc
- Supplements: Iron \& Folic Acid tablets, Vitamin D, Calcium supplements
○ Etc

- Medications notified by Government of India in case from time to time on an Emergency basis

- Such as Chloroquine for Malaria control for a specific endemic region, when notified by Government

\section{List A}

- First Consult Medications (Diagnosis done on video mode of consultation) such as

- Ointments/Lotion for skin ailments: Ointments Clotrimazole, Mupirocin, Calamine Lotion, Benzyl Benzoate Lotion etc

- Local Ophthalmological drops such as: Ciprofloxacillin for Conjunctivitis, etc

- Local Ear Drops such as: Clotrimazole ear drops, drops for ear wax etc..

- Follow-up consult for above medications

- Follow-up medications for chronic illnesses for 're-fill' (on any mode of consultation) such as medications for

- Hypertension: Enalapril, Atenolol etc

- Diabetes: Metformin, Glibenclamide etc

- Asthma: Salmetrol inhaler etc

- Etc

\section{List B}

- On follow-up, medications prescribed as 'Add-on' to ongoing chronic medications to optimize management such as for hYpertension: Eg, add-on of Thiazide diuretic with Atenolol

- Diabetes: Addition of Sitagliptin to Metformin

○ Etc 
This page is intentionally left blank 
REGISTERED MEDICAL PRACTITIONER'S NAME

QUALIFICATION

REGISTRATION NUMBER

ADDRESS

CONTACT DETAILS (EMAIL AND PHONE NUMBER)
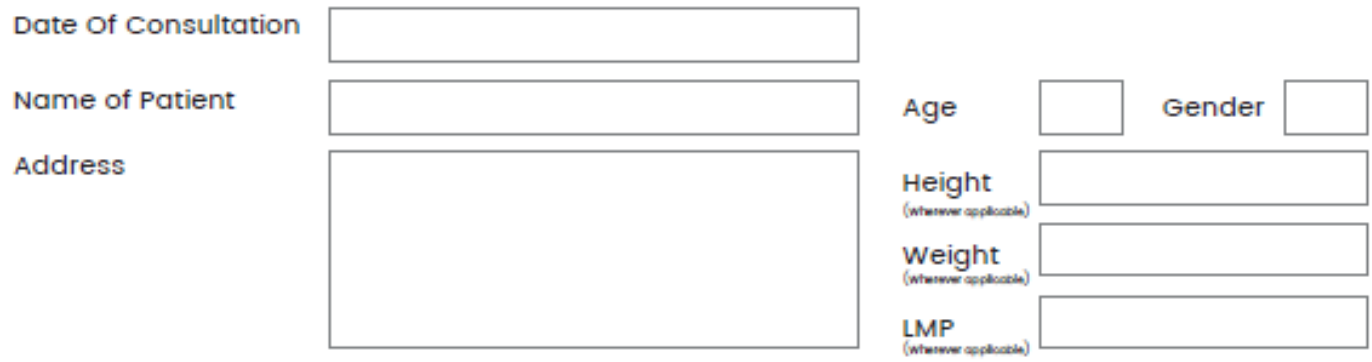

CHEF COMPLANTS

DIAGNOSIS OR PROVISIONAL DIAGNOSIS

REEVANT POINTS FROM HSTORY

$\mathbf{B}$

EXAMINATION / LAB FINDINOS

1. NAME OF MEDICINE (in capital letters only withgeneric name) drug form, strength, frequency of administration \& duration.

2. NAME OF MEDICINE (in capital letters only withgeneric name) drug form, strength frequency of administration \& duration.

SUGGESTEDINVESTIOATIONS

3. NAME OF MEDICINE (in capital letters only withgeneric name) drug form, strength, frequency of administration \& duration. 
This page is intentionally left blank 